\title{
An Investigation into the Relationship between Turkish EFL Teachers' Self-Efficacy and Burnout Level
}

Betül Özkara ${ }^{1}$

\begin{abstract}
The present study investigated whether or not there is an association between self-efficacy beliefs and burnout levels. The study also investigated the effects of such predictor variables as gender, age, teaching experience, average number of students in classrooms on the three dimensions of teacher burnout (emotional exhaustion, depersonalization, and personal accomplishment) and self-efficacy. 118 Turkish EFL teachers from primary, secondary, high schools and universities in many cities participated in the study. Maslach Burnout Inventory (MBI) (Maslach and Jackson, 1981; Huang, 1988), and language teacher self-efficacy beliefs scale (Praver, 2014) were used in the study. Findings showed that there was a significant positive relationship between self-efficacy and personal accomplishment and a negative relationship between emotional exhaustion and self-efficacy. On the other hand, the results showed a negative relationship between emotional exhaustion and personal accomplishment and a negative relationship between personal accomplishment and depersonalization. Generally, teachers felt sufficient, had high self-accomplishment and they had low burnout level. In addition, age had significant role on self-efficacy, and experience were also found to play an important role in personal accomplishment.
\end{abstract}

Keywords: Burnout, Self-Efficacy, EFL Teachers.

\section{INTRODUCTION}

There have been various approaches to improve English language education for the last several decades. Some of these approaches include traditional, structure-based to the communicative approach. All these approaches benefited English language teaching to some degree and provided students of English with a variety of ways to learn English better (e.g. interactive and communicative methods which prioritize students' different needs to be met). While these approaches had many advantages for students who need different type of learning strategy, they fell short of meeting the language educators' need and concerns. For example, teachers' identity problems have been overlooked, their problems have remained unresolved and their skills have been viewed as insufficient in the context of language teaching with different approaches. Lack of supportive approaches that would help teachers/instructors to struggle with their emotional problem will result in a teachers' burn out, which is currently a conspicuous research topic in literature.

Maslach (2003) defined burnout as a psychological syndrome that involves a prolonged response to stressors in the workplace' (p. 189). According to Maslach, burnout involves three concepts: cynicism, emotional exhaustion, and a sense of inefficacy. While exhaustion means being emotionally tired, cynicism means holding a depersonalized attitude towards people, and a sense of inefficacy means

${ }^{1}$ MA, Sakarya University, Institute of Educational Sciences, betul.trkmn@gmail.com 
undervaluing himself (Maslach, 2003). While these three concepts constitute core elements of burn out, the relationship between self-efficacy and burnout is more emphasized by the recent literature (Bümen, 2010; Brudnik, 2009; Evers, Brouwers, \& Tomic, 2002; Mede, 2009; Sakiz \& Saricam, 2014).

Bandura (1994) defined self-efficacy as "people's beliefs about their capabilities to produce designated levels of performance that exercise influence over events that affect their lives. Self-efficacy beliefs determine how people feel, think, motivate themselves and behave" (p. 2). Self-efficacy plays an important role in people's motivation, behavior, feeling, and resistance to failure. People with low selfefficacy are vulnerable to stress and depression because they see challenges as something that they cannot overcome by themselves. In the context of language teaching, self-efficacy is very relevant concept since the stress teachers feel because of difficulties they face in regard to classroom management, failure to meet the requirements of institution and authorities causes lack of confidence in themselves, and ruin their self-efficacy. The outcome of this situation is tiredness and depression.

Therefore, this study aimed to investigate this relationship between self-efficacy and burn-out levels that take place among English language teachers in Turkey. It is the argument that while teachers, on one hand, prepare their students for a bright future, on the other hand, they are responsible to parents, administrators, and colleagues which puts heavy workload and stress on their shoulders. In this context, it is important to understand to what extent language teachers experience lack of self-efficacy and whether or not this leads to burn out. Thus, the main aim of the present research study was to first explore the relationship between Turkish EFL teachers' self-efficacy and burnout level, and then to look into the effects of such variables as gender, age, teaching experience, average number of students in classrooms which are taught to be a source of burnout on this relationship.

\section{LITERATURE REVIEW}

The relationship between teachers' self-efficacy and burnout has been studied extensively in the field of English language teaching as the role of teachers is considered to be highly crucial (Evers, et al., 2002; Mede, 2009; Sakiz \& Saricam, 2014). The degree of protection of self-efficacy of teachers against burnout was studied by Brudnik (2009) who emphasized that self-efficacy protected teachers from the components of burnout syndrome such as depersonalization, emotional exhaustion, and reduced selfaccomplishment. Another study on the same line (Bümen, 2010) found that there was a strong and negative correlation between self-efficacy and burnout level, meaning that the lower burnout, the higher self-efficacy. Moreover, Evers et al. (2002) reported that there was a relationship between self-efficacy beliefs of teachers and dimensions of burnout level, personal accomplishment. They found that teachers with low self-efficacy suffered from emotional exhaustion and therefore they scored lower on their personal accomplishment.

Individual differences are viewed as the main variables in both self-efficacy and burnout studies. Gender, for instance, is a noticeable factor related to teachers' burnout. More specifically, Saricam and Sakiz (2014) in their study found that female teachers had higher burnout level than male teachers, but there was no significant difference related to self-efficacy level. According to the results of another study conducted by Lau, Yuen, and Chan (2005), while emotional exhaustion and low self-accomplishment were found for female teachers at a higher level, depersonalization was not found significant. 
In addition, age has been considered an effective factor in burnout. Research in this area shed light on how teachers' age is related to burnout level and perceived self-efficacy. Lau et al. (2005) found that younger teachers' burn out level was higher than those of older ones. Also, a study done by Mede (2009) verified the same result that younger teachers had a higher level of burnout. However, another study done by Williams and Dike (2015) showed a conflicting result, according to the study result, older and experienced teachers were more vulnerable to be burnout.

Another factor that has a relationship with teacher burnout level is teachers' experience. It was found that inexperienced teachers suffered more from burnout (Bumen, 2010). In another study, more experienced teachers found to have a lower score in emotional exhaustion and reduced personal accomplishment while less experienced teacher scored lower in depersonalization (Mede, 2009). Similarly, Lau et al. (2005) found that unmarried teachers with less experience and at junior rank, without religious belief, and without professional training showed greater burnout syndrome. However, one study found a conflicting result reporting that there was a positive correlation between teachers' experience and burnout (Williams \& Dike, 2015).

The literature from Turkey is also similar to research reporting mixed findings. For example, in one study Demirel and Cephe (2015) found that there was a tendency to higher burnout among young and novice teachers. However, in another study researchers found opposite findings, Ozkanal and Arıan (2010) reported that demographic features did not have a significant correlation with burnout level, and there was not remarkable burnout level among the participants. In addition, Unaldi, Bardakci, Dolas, and Arpaci (2013) found that teachers' personality traits were also a crucial factor for burnout. While teachers' neuroticism could be seen as one of the reasons of burnout, teachers' one of the personality traits: 'extraversion,' 'agreeableness', 'conscientiousness' and 'openness to experience' had a positive effect on personal achievement (p. 95).

The current study is important because it investigated the English language teachers' burnout and selfefficacy levels and explored whether or not there is a relationship between these two. Moreover, the study yielded important findings with regard to the association between teacher's burn out and selfefficacy level and also about the effects of predictor variables on this association. The research questions addressed in the present study are as follows:

1. What is the relationship between Turkish EFL teachers' self-efficacy and burn out level?

2. What is the relationship between the three dimensions of burnout, self-efficacy and gender?

3. What is the relationship between the three dimensions of burnout, self-efficacy and age?

4. What is the relationship between three dimensions of burnout, self-efficacy and teaching experience?

5. What is the relationship between the three dimensions of burnout, self-efficacy and the average number of students in classrooms?

\section{METHODOLOGY}

The present study investigated the Turkish EFL teachers' self-efficacy and burn out level and also investigated predictor factors such as gender, age, teaching experience, average number of students in 
classrooms and their impact on these teachers' self-efficacy and burn out level. The study used quantitative method and collected data through questionnaires. The current research was done by asking teachers to respond 6 point Likert scale which is a language teacher efficacy beliefs scale developed at a Japanese university (Praver, 2014) and 5 point Likert scale Maslach Burnout Inventory (MBI) (Maslach \& Jackson, 1981). Moreover, rather than a paper-based form, to reach more varied teachers from different cities and institutions, online questionnaire forms were created. To maximize the effectiveness of the study, the questionnaires were piloted once. Participants were chosen on the basis of purposive of sampling. Only Turkish EFL teachers participated in this study.

\section{Setting and Participants}

Participants in this study included 118 EFL teachers from primary, secondary and high schools and universities in different cities. Out of 118 respondents, 86 were females and 32 were males. The participants whose ages range from 23 to 35 constituted the largest group of participants, whereas the participants' age between 46 to 55 constituted the smallest group of participants. Variation between age groups were done in order to make a healthy mix of younger and older teachers. To be the participant of the study, all the teachers were EFL teachers and were NNS (non-native speaker) of English.

\section{Data Collection Instruments}

\section{Self-efficacy survey}

Japanese university language teacher efficacy beliefs scale developed by Max Praver (2014) was used to measure perceived self-efficacy of teachers. The survey included 32 items. Teachers were asked to respond to a 6 point Likert scale which allows the participants to choose from strongly disagree (1) to strongly agree (6).

\section{Burn out Scale}

Maslach Burnout Inventory (MBI) was developed by Maslach and Jackson (1981) and Huang (1988) which was used to assess three main components of burnout: Emotional Exhaustion, Depersonalization, and Personal Accomplishment. The survey included 22 items, while 9 of which measure emotional exhaustion, the other 5 items measure depersonalization, and the other 8 items measure personal accomplishment. Teachers were asked to respond to a 5 point- Likert scale which allows the participants to choose from never (1) to always (5).

\section{Data Analysis}

The data analysis for descriptive statistics and frequency analysis were conducted, and further correlation analyses were run to establish the relationship between certain variables, self-efficacy and burnout level. As data set did not normally distribute, data were analyzed using the Spearman Rho test of Correlation to describe the linear relationships between perceived self-efficacy and the three dimensions of teacher burnout (emotional exhaustion, depersonalization, and personal accomplishment). Man Whitney U test and Kruskal-Wallis were used to understand the probable effect of teachers' personal variables including gender, age, teaching experience and average number of students in classrooms on the three dimensions of teacher burnout. 


\section{FINDINGS}

As it was stated previously this current study analyzed the relationship between teachers' self-efficacy and burnout level and also analyzed the impact of predictor variable (age, gender, experience and average number of students in the classroom) on self-efficacy and burnout level. The following presents the findings for each of the five research questions listed above.

\section{Median Results of the Relationship between Self-Efficacy and Burnout Level}

In self-efficacy survey which included 32 items, 23 items received median ratings of 5 (Agree), and the rest of the items received median ratings of 4 (Slightly Agree). When it comes to the burnout survey which included 22 items, it was found that 8 items received median ratings of 4 (usually); these 8 items belong to one of the subcategories of burnout survey, self-accomplishment. 4 Items received median ratings of 3 (sometimes), 8 items received median ratings of 2 (Seldom) and 2 items received median ratings of 1 (never).

\section{The Relationship between Self Efficacy and Burnout Level}

Data were analyzed by using the Spearman Rho test of Correlation to describe the linear relationships between two variables, perceived self-efficacy and the three dimensions of teacher burnout (emotional exhaustion, depersonalization, and personal accomplishment). Preliminary analyses were performed to ensure no violation of the assumptions of normality, linearity, and homoscedasticity. There was a medium level correlation between self-efficacy and personal accomplishment variables $[r=0.458, \mathrm{~N}=$ $118, p<0.05]$ with high-level self-efficacy with high personal accomplishment. Moreover, there was a medium level negative correlation between self-efficacy and emotional exhaustion variables $(r=-.182, \mathrm{~N}$ $=118, p<0.05$ ) with a high level of self-efficacy and low level of emotional exhaustion. There was a strong correlation between two burnout subtypes Emotional Exhaustion and Depersonalization variables $(r=.682, \mathrm{~N}=118, p<0.05)$ with high-level emotional exhaustion and with high depersonalization. In addition to that there was a negative correlation between emotional exhaustion and personal accomplishment variables $(r=-.230, \mathrm{~N}=118, p<0.05)$. The moderate negative correlation was found between personal accomplishment and depersonalization variables $(r=-.333, \mathrm{~N}=118, p<$ 0.05 ) with a low level of personal accomplishment and high level of depersonalization. Table 1 displays summary results of the statistics of self-efficacy, emotional exhaustion, depersonalization, and personal accomplishment scales (see below).

\section{Table 1}

Descriptive Statistics of Self-efficacy, Emotional Exhaustion, Depersonalization, and Personal Accomplishment Survey Scales.

\begin{tabular}{lllll}
\hline & & 1 & 2 & 3 \\
\hline Spearman's rho & Self-efficacy & $-.182^{*}$ & -.165 & $.458^{* *}$ \\
& Emotional Exhaustion & & $.682^{* *}$ & $-.230^{*}$ \\
& Depersonalization & & $-.333^{* *}$ \\
\hline
\end{tabular}




\section{Effect of Predictor variables on Self-Efficacy and Burnout Level.}

The current study investigated the influence of some of the demographic variables on teachers' selfefficacy and burn-out level. Man Whitney $U$ test and Kruskal-Wallis were used to understand the probable effect of teachers' personal variables including gender, age, teaching experience, average number of students in classrooms on the three dimensions of teacher burnout (emotional exhaustion, depersonalization, and personal accomplishment). The findings point to an important effect of some of the predictor variables on teachers' self-efficacy and burnout level. For example, among the personal variables, there was found a significant relationship between self-efficacy and age. It was also found a remarkable relationship between one of the components of burnout, personal accomplishment, and experience. This section presents the effect of demographic variables in more detail way.

\section{Gender}

Man Whitney U Test was conducted to compare the self-efficacy level for males and females. There was no significant difference for males $(\bar{x}=51.69, \mathrm{M}=32$ ) and females $(\bar{X}=62.4, \mathrm{~N}=86) t=-1.535, p=.125]$. The magnitude of the differences in means is very small. The comparison of emotional exhaustion level for gender difference shows that there was no significant difference in levels for males $(\bar{X}=66.44$,$) and$ females $(\bar{X}=56.92 t=-1.363, p=.173]$. When it comes to depersonalization there was not a significant difference between males $(\bar{X}=67.22)$ and females $(\bar{X}=56.63 p=.125 t=-1.533)$. Also, there was not a considerable difference between male $(\bar{X}=56.08)$ and females $(\bar{X}=60.77 p=498 t=-.678)$ in personal accomplishment.

\section{Age}

Kruskal-Wallis of variance was conducted to explore the impact of age on self-efficacy, emotional exhaustion, depersonalization, and personal accomplishment. The ages are grouped into three levels: 23-35, 36-45, and 46-55 years old. The test results are summarized in Table 2. There was a significant difference between self-efficacy and all three age groups ( $p<0.0523-35 \mathrm{yrs}$. N = $92 \mathrm{md}=56,37,36-45$ yrs. $\mathrm{N}=20 \mathrm{md}=76,68$ and $46-55 \mathrm{yrs} . \mathrm{N}=6 \mathrm{md}=50,25)$; 36-45 years' age group recorded higher median score than the other two age groups. Moreover, post hoc tests were used to test pairwise comparisons. It indicated that there was no significant difference between groups. There was no significant difference in emotional exhaustion, depersonalization and personal accomplishment regarding the age of teachers $(p$ $>0.05)$. 


\section{Table 2}

The Test Scores for All Test Depending On Age

\begin{tabular}{|c|c|c|c|c|}
\hline & & $\mathrm{N}$ & $\bar{x}$ & $p$ \\
\hline \multirow{4}{*}{ Self-efficacy } & $23-35$ & 92 & 56.37 & \multirow{4}{*}{.040} \\
\hline & $36-45$ & 20 & 76.68 & \\
\hline & $46-55$ & 6 & \multirow[t]{2}{*}{50.25} & \\
\hline & Total & 118 & & \\
\hline \multirow{4}{*}{ Emotional Exhaustion } & $23-35$ & 92 & 59.78 & \multirow{4}{*}{.609} \\
\hline & $36-45$ & 20 & 62.08 & \\
\hline & $46-55$ & 6 & 46.67 & \\
\hline & Total & 118 & & \\
\hline \multirow{4}{*}{ Depersonalization } & $23-35$ & 92 & 60.55 & \multirow{4}{*}{.594} \\
\hline & $36-45$ & 20 & 52.95 & \\
\hline & $46-55$ & 6 & 65.25 & \\
\hline & Total & 118 & & \\
\hline \multirow{4}{*}{ Personal Accomplishment } & $23-35$ & 92 & 56.69 & \multirow{4}{*}{.228} \\
\hline & $36-45$ & 20 & 69.73 & \\
\hline & $46-55$ & 6 & 68.50 & \\
\hline & Total & 118 & & \\
\hline
\end{tabular}

\section{Experience}

The teachers' years of experience were classified into three groups. Group 1 consisted of 1-6 years of experience, Group 2 constituted 6-15 year of experience, and Group 3 consisted of 16-more years of experience. There was no significant difference at the $p>0.05$ level between self-efficacy and teachers' years of experience (Group 1, N = 41; 1-6, Group 2, N = 64; 6-15, Group 3, N =13; 16+, $p=.82$ ).

There was no significant difference at the $p>0.05$ level in emotional exhaustion for experience groups (Group 1, N = 41; 1-6, Group2, N = 64; 6-15, Group 3, N = 13; 16+, $p=.32$ ). There was no significant difference at the $p>0.05$ level in depersonalization for experience groups (Group 1, N = 41; 1-5, Group 2, $\mathrm{N}=64 ; 6-15$, Group $3, \mathrm{~N}=13 ; 16+, p=.63$ ). There was a significant difference at the $p<0.05$ level in personal accomplishment for experience groups (Group 1, N = 41; 1-6, Group 2, N = 64; 6-15, Group 3, N $=13 ; 16+, p=.002$ ). Personal Accomplishment score of 16-more experience (Group 3) was higher than the other groups. Moreover, the 6-15 years of total teaching experience (Group 2) had higher scores than the 1-6 years of total teaching experience (Group 1). Post hoc test was conducted to test pairwise comparisons and it was discovered that Group 1 was significantly different from Group 3. There was no 
significant difference between Group 1 and Group 2, Group 2 and Group 3. The score of the subtests shown in Table 3.

\section{Table 3}

The Test Scores for All Test Depending On Experience Group

\begin{tabular}{lllll}
\hline & Groups & N & Mean Rank & $p$ \\
\hline Self - Efficacy & $1-5$ & 41 & 58.16 & \\
& $6-15$ & 64 & 59.27 & .821 \\
& $16-30$ & 13 & 64.85 & \\
& Total & 118 & & \\
\hline \multirow{3}{*}{ Emotional Exhaustion } & $1-5$ & 41 & 58.12 & \\
& $6-15$ & 64 & 62.79 & \\
& $16-30$ & 13 & 47.65 & .320 \\
& Total & 118 & & \\
Depersonalization & $1-5$ & 41 & 60.13 & \\
& $6-15$ & 64 & 60.77 & \\
& $16-30$ & 13 & 51.23 & .635 \\
& Total & 118 & & \\
\hline \multirow{3}{*}{ Personal Accomplishment } & $1-5$ & 41 & 47.82 & \\
& $6-15$ & 64 & 62.07 & \\
& $16-30$ & 13 & 83.69 & \\
& Total & 118 & & \\
\hline
\end{tabular}

\section{Average Number of Students in Classrooms}

Kruskal-Wallis of variance was conducted to explore the impact of the average number of students in classrooms. The average student numbers teachers have in a classroom are divided into three groups: 1$15,16-25$ and 26+. There was no significant difference at the $p<0.05$ level among the groups in their effects on the self-efficacy (Group 1, N = 33; 1-15, Group 2, N = 54; 16-25, Group 3, N = 31; 26+, $p=.49$ ) and also on the three dimension of burnout level (emotional exhaustion $p=.22$, depersonalization $p=.79$ personal accomplishment $p=.61$ ).

\section{DISCUSSION}

This study investigated whether or not there is any relationship between self-efficacy levels of English teachers and the three dimensions of teachers' burnout levels (emotional exhaustion, depersonalization, and personal accomplishment). In addition, the study examined the impact of such demographic 
variables as gender, age, teachers' years of experience, average number of students in Turkish EFL context.

In self-efficacy survey, of all the 32 items, 23 items were rated 5 (agree) while the rest of the items were rated 4 (slightly agree). This result indicated that teachers' perceived self-efficacy levels were high, namely, they feel competent in doing their job. When it comes to the burnout survey, of all the 22 items only 8 items were rated 4 (usually). These eight items belong to one of the subtypes of burnout survey, personal accomplishment. These results demonstrated that teachers had high self-efficacy and personal accomplishment. In addition, further data analyses confirmed the same result. It was found a positive correlation between teachers' self-efficacy and their personal accomplishment, with higher self-efficacy leading to higher personal accomplishment. This finding is in line with the findings of previous studies (Sakiz and Saricam, 2014; Bümen, 2010; Evers, et al., 2002; Cephe, 2010) which reported positive association between self-efficacy and personal accomplishment.

However, when it comes to the other subtypes of burnout, 4 items were rated 3 (sometimes), 8 items received 2 (seldom) and 2 items received 1 (never). These results indicated that teachers found themselves sufficient and they did not have feelings of burnout in their teaching job. Therefore, it could be reached a conclusion that having higher self-efficacy leads to lower general burnout level which was also confirmed by an extensive literature (see Brudnik 2009; Evers et al., 2002; Mede 2009; Sakiz and Saricam, 2014). While medium level negative correlation was found between self-efficacy and emotional exhaustion; moreover, there was no correlation between self-efficacy and depersonalization. In addition, the results of the study indicated that there was a negative correlation between emotional exhaustion and personal accomplishment and there was a medium level negative correlation between personal accomplishment and depersonalization. These results indicated that higher self-efficacy equals to lower emotional exhaustion and higher personal accomplishment equals to lower depersonalization.

In addition, in this study, it was found that there was a significant relationship between teachers' demographic characteristics (age and years of experience) and three components of burnout and selfefficacy. One component of burnout, personal accomplishment, showed variation with regard to experience. For example, personal accomplishment was higher amongst teachers who have longer work experience (16-more experience) teacher. Put it differently, having longer work experience makes the teachers feel more accomplished and confident in their job. The findings of the study are consistent with extensive previous research, for example, Anderson and Iwanicki (1984) indicated a similar result that experienced teachers (13-24 years) score lower in reduced personal accomplishment. They called this situation as "plateau period in teaching career" (p. 123-124). Moreover, in their study Tschannen-Moran and Hoy (2007) found that less experienced teachers who had three or less than three years of experience had lower self-efficacy compared to more experienced teachers who had four or more years of experiences. However, Shohani, Azizifar, Gowhary, and Jamalinesari, (2015) explained this situation as, while novice teachers were evaluating their general self-efficacy, they could count in their failure on the control few students' inappropriate behaviors, on the other hand, experienced teachers think it as a normal situation and they do not include this situation while they are evaluating their performance. Moreover, Gavish and Friedman (2010) examined new teachers' burnout level According to the result of their study both at the start and at end of the term, new teachers' burnout levels were high. 
With respect to age, findings showed a positive relationship between age and self-efficacy. According to the results of the study, 36-45 age groups had higher self-efficacy than the other age groups (23-35 yrs. and 46-55 yrs.). In regard to age, the result is consistent with a study conducted by Anderson and Iwaniki (1984) who discovered that younger teachers scored higher in emotional exhaustion.

When it comes one of the demographic variables, gender there was not found any relation between three components of burnout, self-efficacy, and gender. While the result of the study is consistent with two recent studies Ozan (2009) and Tschannen-Moran and Hoy (2007) who did not find any relation between self-efficacy and gender. The results of the study was not similar to other studies who found an association between burnout, self-efficacy, and gender. For example, contrary to our findings, Anderson and Iwanicki (1984) showed that male teachers were more liable to burnout compared to female teachers. Freidman (1991) investigated that high burnout level institutions had more male teachers and Deryakulu (2005) confirmed that male teacher had higher level of general burnout.

Finally, regarding average number of students in the classroom, there was not found any significant association between the number of students in a classroom and burn out level, which indicates that number of students in a classroom has no effect on teachers' burnout level. Our finding is different from findings of some of the studies who found that there was a strong relationship between the population of the classroom and burn out levels. For example, Ozdemir (2007) examined 523 teachers' classroom management efficacy and burnout level, teachers who had less classroom management efficacy, had higher level burnout. Cemaloglu and Sahin (2007) investigated 515 teachers' burnout level regarding some variables. They found that higher number of students in the classroom, ignorance from the school board, teachers' reluctance and inadequate emotional satisfaction were one of the factors that affect three dimensions of burnout. Bumen (2010) also confirmed the same result.

\section{IMPLICATIONS AND CONCLUSION}

English teachers' self-efficacy and its relation to burnout is a popular topic in the literature. However, in Turkish context this issue is little studied, Therefore, this study aimed to fill this gap and investigated the relationship between self-efficacy and teachers' burnout as well as demographic data on the three dimensions of teacher burnout (emotional exhaustion, depersonalization, and personal accomplishment) in Turkish EFL teachers. There was not found any significant connection between teachers' self-efficacy and their burnout level. It was also found the impact of demographic variables as age, teachers' experience on this association.

Burnout is an inevitable reality among English teachers, that's why governments and school administers, should not see it as a negligible subject. The results of our study provide information to administrators and policymakers about the fact that English teachers' self-efficacy is significantly related to the burnout level. Moreover, for the in-service teachers, institutes of higher education should provide specific classes for real life teaching situation. Even though Kulekci (2011) found that pre-service English teachers' grade level and academic achievement affected their self-efficacy level, Ortactepe and Akyel (2015) argued that in-service teacher education programs made a contribution to EFL teachers' selfefficacy. 
Even though our study has important findings and implications for policy makers, it has some limitations. The target participants of this study was Turkish EFL teachers and our sample size was limited to 118 teachers, therefore the results of this study are not generalizable to wider population. In addition, participants represented in this study were unevenly distributed in terms of age, gender, and experience. The small size of the 46-55 age group placed a limitation on the interpretation of the study's result on the analysis of age difference. It could be suggested that future research should explore teachers' self-efficacy and burnout relation in a longitudinal study and also, qualitative studies on the relation between teacher burnout, self-efficacy, and diverse demographic data could be carried out to get insights into participants' feelings in more detail. Finally, cross-country comparisons of English teachers' burnout and self-efficacy level could be advocated to see how different demographic variables effect this association.

\section{REFERENCES}

Anderson, M. B. G., \& Iwanicki, E. F. (1984). Teacher motivation and its relationship to burnout. Educational Administration Quarterly, 20(2), 109-132.

Bandura, A. (1994). Self-efficacy. In V. S. Ramachaudran (Ed), Encyclopedia of human behavior (Vol. 4, pp.71-81). New York: Academic Press. Reprinted in H. Friedman [Ed.], Encyclopedia of mental health. San Diego: Academic Press.

Bauer, J., Stamm, A., Virnich, K., Wissing, K., Müller, U., Wirsching, M., \& Schaarschmidt, U. (2006). Correlation between burnout syndrome and psychological and psychosomatic symptoms among teachers. International Archives of Occupational and Environmental Health, 79(3), 199-204.

Brudnik, M. (2009). Perception of self-efficacy and professional burnout in general education teachers. Human movement, 10(2), 170-175.

Bümen, N. T. (2010). The relationship between demographics, self efficacy, and burnout among teachers. Eurasian Journal of Educational Research, 40, 17-36.

Cemaloğlu, N., \& Şahin, D. E. (2007). Öğretmenlerin mesleki tükenmişlik düzeylerinin farklı değişkenlere göre incelenmesi. Kastamonu Ĕ̆itim Dergisi, 15(2), 465-484.

Cephe, P. T. (2010). A study of the factors leading English teachers to burnout. Hacettepe Üniversitesi Ĕgitim Fakültesi Dergisi, 38, 25-34.

Demirel, E. E., \& Cephe, P. T. (2015). Looking into burnout levels among English language instructors. Journal of Language and Linguistic Studies, 11(1), 1-14.

Deryakulu, D. (2005). Bilgisayar öğretmenlerinin tükenmişlik düzeylerinin incelenmesi. Eurasian Journal of Educational Research, 19, 35-53.

Dörnyei, Z. (2007). Research methods in applied linguistics: Quantitative, qualitative, and mixed methodologies. Oxford University Press. 
Evers, W. J., Brouwers, A., \& Tomic, W. (2002). Burnout and self-efficacy: A study on teachers' beliefs when implementing an innovative educational system in the Netherlands. British Journal of Educational Psychology, 72(2), 227-243.

Friedman, I. A. (1991). High and low-burnout schools: School culture aspects of teacher burnout. The Journal of Educational Research, 84(6), 325-333.

Gavish, B., \& Friedman, I. A. (2010). Novice teachers' experience of teaching: A dynamic aspect of burnout. Social Psychology of Education, 13(2), 141-167.

Huang, H. (1988). The effect of social support on teacher stress and teacher burnout (Doctoral Dissertation) (Order No. 8816477). Available from ProQuest Dissertations \& Theses Global. (303581578). Retrieved from http://search.proquest.com/docview/303581578?accountid=13654

Klassen, R. M., \& Chiu, M. M. (2010). Effects on teachers' self-efficacy and job satisfaction: Teacher gender, years of experience, and job stress. Journal of Educational Psychology, 102(3), 741.

Külekçi, G. (2011). A study on pre-service English teachers' self-efficacy beliefs depending on some variables. International Online Journal of Educational Sciences, 3(1), 245-260.

Lackritz, J. R. (2004). Exploring burnout among university faculty: incidence, performance, and demographic issues. Teaching and Teacher Education, 20(7), 713-729.

Lau, P. S., Yuen, M. T., \& Chan, R. M. (2005). Do demographic characteristics make a difference to burnout among Hong Kong secondary school teachers? Social Indicators Research, 71, 491-516.

Martin, N. K., Sass, D. A., \& Schmitt, T. A. (2012). Teacher efficacy in student engagement, instructional management, student stressors, and burnout: a theoretical model using in-class variables to predict teachers' intent-to-leave. Teaching and Teacher Education, 28(4), 546-559.

Maslach, C. (2003). Job burnout new directions in research and intervention. Current Directions in Psychological Science, 12(5), 189-192.

Maslach, C., \& Jackson, S. E. (1981). The measurement of experienced burnout. Journal of Organizational Behavior, 2(2), 99-113.

Praver, M. (2014). Japanese university English language teachers' self-efficacy beliefs: A 171 mixed-methods exploration. (Doctoral dissertation, Temple University Libraries).

Mede, E. (2009). An Analysis of Relations among Personal Variables Perceived Self Efficacy and Social Support on Burnout among Turkish EFL Teachers. Inonu University Journal of the Faculty of Education, 10(2), 39-52.

Ortaçtepe, D., \& Akyel, A. S. (2015). The effects of a professional development program on English as a foreign language teachers' efficacy and classroom practice. Tesol Journal, 6(4), 680-706.

Ozan, M. B. (2009). A study on primary school teacher burnout levels: The Northern Cyprus Case. Education, 129(4), 692-703.

Ozdemir, Y. (2007). The role of classroom management efficacy in predicting teacher burnout. International Journal of Social Sciences, 2(4), 257-263. 
Özkanal, Ü., \& Arikan, N. (2010). Investigation of burnout among instructors working at ESOGU preparatory school. English Language Teaching, 3(1), 166-172.

Praver, M., Churchill, E., Irie, K., Burrows, L., \& Elwood, J. A. (2014). Japanese University English language teachers' self-efficacy beliefs: a mixed-methods exploration. (Doctoral dissertation) (Order No. 3623235). Available from ProQuest Dissertations \& Theses Global (1548984893) Retrieved from http://search.proquest.com/docview/1548984893?accountid=13654

Sarıçam, H., \& Sakız, H. (2014) Burnout and teacher self-efficacy among teachers working in special education institutions in Turkey. Educational Studies, 40(4), 423-437.

Sari, H. (2004) An analysis of burnout and job satisfaction among Turkish special school head teachers and teachers, and the factors effecting their burnout and job satisfaction. Educational Studies, 30(3), 291-306.

Shaukat, S., \& Iqbal, H. M. (2012). Teacher self-efficacy as a function of student engagement, instructional strategies and classroom management. Pakistan Journal of Social and Clinical Psychology, 9(3), 82-85.

Shohani, S., Azizifar, A., Gowhary, H., \& Jamalinesari, A. (2015). The relationship between novice and experienced teachers' self-efficacy for personal teaching and external influences. Procedia Social and Behavioral Sciences, 185 (The Proceedings of 3rd World Conference on Psychology and Sociology), 446-452.

Tschannen-Moran, M., \& Hoy, A. W. (2007). The differential antecedents of self-efficacy beliefs of novice and experienced teachers. Teaching and Teacher Education, 23(6), 944-956.Topkaya, E. Z., \& Yavu, A. (2011). Democratic Values and Teacher Self-Efficacy Perceptions: A Case of Pre-Service English Language Teachers in Turkey. Australian Journal of Teacher Education, 36(8), 32-49.

Unaldi, I., Bardakci, M., Dolas, F., \& Arpaci, D. (2013). The relationship between occupational burnout and personality traits of Turkish EFL teachers. Journal of Education and Practice, 4(13), 86-98.

Williams, J., \& Dikes, C. (2015). The implications of demographic variables as related to burnout among a sample of special education teachers. Education, 135(3), 337-345. 